\title{
Managed care and ethical conflicts: anything new?
}

\author{
Christopher Meyers California State University, Bakersfield, USA
}

\begin{abstract}
Does managed care represent the death knell for the ethical provision of medical care? Much of the current literature suggests as much. In this essay I argue that the types of ethical conflicts brought on by managed care are, in fact, similar to those long faced by physicians and by other professionals. Managed care presents new, but not fundamentally different, factors to be considered in medical decision making. I also suggest ways of better understanding and resolving these conflicts, in part by distinguishing among conflicts of interest, of bias and of obligation.
\end{abstract}

(Fournal of Medical Ethics 1999;25:382-387)

Keywords: Managed care; conflicts of interest; medical decision making; bias; obligation

"The death of medicine is upon us", or so one might conclude, reading some of the recent reactions to the proliferation of managed care programmes. Articles, from all quarters of health care, ${ }^{1}$ decry the erosion of the relationship between patients and physicians ${ }^{2}$ and patients and nurses. ${ }^{3}$ They lament the "new" conflicts of interest present in managed care. ${ }^{4}$ They worry about the potential harms to patients. ${ }^{5}$ There is even talk of physicians forming unions as a way of combating the managed care threat. ${ }^{6}$

Managed care has also motivated ethics centres such as the Kennedy Institute of Ethics to devote entire workshops to the potential problems. And all this is but a whisper compared to physicians' daily conversations. Gather together two or more and likely as not the topic will eventually find its way to the horrors managed care has wrought upon medicine in the United States. ${ }^{7}$

There are undoubtedly numerous new ethical issues emerging from managed care, just as new problems and concerns arise with any broad change in an occupation or profession. My claim in this paper, however, is that despite the many assertions to the contrary, the ethical issues associated with managed care are not fundamentally different from those physicians have always faced. My position is that the changes represent not the dire threat to patient wellbeing which much of the literature maintains, but rather a threat physicians' clinical autonomy and control.

My goal is not to defend managed care in gerto eral. Its medical and economic benefits and harms are far from fully resolved. There is evidence that managed care is not saving money, just shifting costs by attempting to exclude from plans patients with greater risk of illness or injury and by "shift-ing a greater proportion of the burden of costs to patients, through increased deductibles and cof insurance requirements, and ... to providers through reduced fees". ${ }^{8}$ On the other hand, ther $\overrightarrow{8}$ is also evidence that under fee-for-service plans overtreatment was so extensive, patients were at greater risk for iatrogenic illness than they are fos undertreatment in managed care. ${ }^{8}$

In this paper I will address only the ethical conf cern most often cited in discussions of the impae of managed care-conflicts of interest. Physician $\vec{\xi}$ routinely, and often angrily, note that the regularly feel caught between patients' need their own autonomy, and their obligations to managed care organisation. And they generally claim that such conflicts are a recent development in medical decision making, that prior to the world of managed care medical decisions were almost exclusively based on what was in the patient's best interest. I will argue that since thig latter claim is clearly false, that since a wide range of factors, many of which have decidedly little to do with patients' best interest, have long influt enced medical decision making, an effective analysis of the ethical concerns associated wit managed care must first determine how decisio 9 making has been changed, and whether such changes are always for the worse. In making the case I will appeal to the too-often overlooked, but conceptually and ethically crucial, distinction among conflicts of interest, of bias, and of obligation. The paper will conclude with som suggestions on how to recognise and wors through such conflicts.

A first caveat: the paper does not attempt to address the much broader question of whether ag altogether different type of health care financint system might not be much preferred, ethically aria 
medically-for example, a government sponsored or other single payer system. I believe such a fundamental change in US health care would almost assuredly be a benefit; most of the conflict of interest problems addressed here would likely disappear. But this paper's focus is much more narrow: does managed care, the system currently in place in much of the United States and likely to be so for years to come, bring with it altogether new kinds of ethical problems, problems that reveal it to be an ethically untenable system, relative to the fee-for-service plans predominant until only a decade ago?

\section{Distinguishing among types of conflicts}

Conflicts of interest emerge out of relationships with defined roles, specifically roles which create morally (or legally) determined expectations of behaviour, for example, doctor-patient, lawyerclient, professor-student, parent-child. A conflict emerges when these expectations run up against competing interests or obligations, whether to self or to others. With rare exception ${ }^{9}$ the medical literature unfortunately lumps together all such conflicts under the general rubric of "conflict of interest". Effective ethical analysis, however, requires noting the differences among the three types of conflicts, since they carry different ethical import and different types of solutions.

Kenneth Kipnis describes the difference between conflicts of interest and of obligation as follows. A conflict of interest exists, he says, when professionals have personal "interests that may incline [them] away from fulfilment of their obligations to clients". ${ }^{10}$ An example would be where a judge attempts to hear a case in which she has a personal stake in the outcome. The fear, of course, is that her personal interest will prevent her from fulfilling her obligations to the litigants, their attorneys, and the community at large.

By contrast, a conflict of obligation occurs when one has at least two moral (or legal) duties present in a situation and when "it is impossible to meet either obligation without compromising one's ability to fulfil the other". ${ }^{11}$ For example, when a state legislator must vote on a bill that will be of clear benefit to the state, but will represent a potential harm to her district.

To Kipnis's analysis I would add a third type of conflict, conflicts of bias. In these conflicts psychological factors exist, often without the agent's explicit awareness, which affect her decision making, typically to the detriment of those to whom she owes obligations. Examples include prejudice (ethnic, racial, religious, agebased, gender-based, etc), denial, and cultural and socialisation factors (for example, values learned in childhood and adolescence).

While not always easy to recognisedetermining when one's judgment is clouded by actual or potential personal gain is often remarkably difficult-conflicts of interest, as defined here, are quite easy to resolve ethically. One must simply set aside one's interest on behalf of the person to whom one owes the competing obligation. $^{12}$

Conflicts of bias are even more difficult to spot, but again they are relatively easy to resolve. Once one realises a bias exists, one must do all one can to set it aside in favour of the obligations owed.

Conflicts of obligation are, by definition, much more ethically troubling. A conflict among competing, role-defined obligations cannot be resolved without violation of an existing duty. Common examples include: a college professor agrees to advise an additional, African-American, thesis student, even though she realises that working with him will compromise her ability effectively to mentor existing advisees; a lawyer takes on a client for whom successful resolution of his case requires revealing confidential information obtained in representing a previous client, and, the kind of example that many in health care currently find so troubling, a physician contracts with a health maintenance organisation (HMO) whose regulations require her to engage in cost-cutting practices that may represent a threat to her patients. In each example the professional has special, and competing, role-engendered obligations to more than one person.

As the physician example reveals, real-world cases usually bring some combination of the three conflicts: ie, part of the reason she has conflicting obligations to the HMO and to her patients is because of her natural desire to earn a decent living, a potential conflict of interest. The reality of each case, however, is that genuine alternatives probably do not exist: the professor may realise that, even stretched thin, she will do a better job of thesis direction than would her bigoted colleague; the attorney may not have realised the clients' cases had any connection until it was too late, and, given the increasingly ubiquitous involvement of HMOs, the physician may not have reasonably alternative ways to practise her chosen profession. Thus the reality brings with it the unavoidable likelihood that conflicts of obligation will emerge.

How then, does one resolve these conflicts? To whom are the greatest obligations owed? Part of the answer lies in recognising that physicians have probably always faced similar conflicts, that medical decisions have long included a variety of factors in addition to "the patient's best interest", 
and that these factors have not precluded the possibility of the ethical practice of medicine.

\section{Factors involved in medical decision making}

One of the most common physician criticisms of managed care is that the new arrangements represent a "radical departure from the traditional physician/patient relationship, wherein the physician is regarded as an advocate for the patient". ${ }^{13}$ The claim is that prior to managed care:

"Medicine [was] at its centre, a moral enterprise grounded in a covenant of trust ... [which] obliges physicians to be competent and to use their competence in the patient's best interests. Physicians, therefore, are both intellectually and morally obliged to act as advocates for the sick wherever their welfare is threatened and for their health at all times." 14

The emergence of managed care, though, has made it such that:

"Today that covenant of trust is significantly threatened. From within, there is growing legitimization of the physician's materialistic selfinterest; from without, for-profit forces press the physician into the role of commercial agent to enhance the profitability of health care organizations." 14

In other words, in the "good old fee-for-service days", so this view holds, physicians almost exclusively made decisions motivated only by what was in their patients' best interest. It has only been with the advent of managed care that the purity of medical decision making has been threatened.

The vast majority of physicians are and were deeply committed to the welfare of their patients. But, as study after study has shown, the vast majority of physicians are also influenced in their medical decision making by factors other than patient wellbeing, factors that include conflicts of interest, of bias, and of obligation. This does not mean physicians, as a group, are less ethically sensitive than other professionals. Humans have exceedingly complex decision making processes wherein multiple factors, many outside the agent's awareness, serve to motivate eventual choices.

In the case of physicians, research has revealed such factors to include all three types of conflict. Under conflicts of interest: physicians' own material gain, whether it be through self-referral practices $^{15}$ or through benefit from relationships with pharmaceutical representatives and the like. ${ }^{16}$ Under conflicts of bias: gender bias, ${ }^{17}$ bias against the aged, ${ }^{18}$ against those with AIDS or HIV, ${ }^{19}$ against gays and lesbians, ${ }^{20}$ against those believed to be leading unhealthy lifestyles, ${ }^{21}$ and even i physicians' preconceived expectations of what they "should" find in clinical examination. ${ }^{22}$ An under conflicts of obligation: covering for less thag fully competent colleagues, pursuing research goals to the potential detriment of patients, an $\bar{A}$ "redefining" a patient's diagnosis so as to make $\mathbb{8}$ fit into third-party-payer guidelines.

Given this wide range of conflicting factors and their near ubiquitous presence in medical decision making, and given the profound impact sucto biases can have on medical decision making, ${ }^{23}$ it both dishonest and ethically problematic to insist the new world of managed care has brought radical departure from the traditional physiciarit patient relationship". It may well have been that the "good old days" patients believed their doctor was acting only in their, the patients', best interest. Existing social relationships and power asym metries served to create and reinforce this fiction But it was a fiction.

Thus, while managed care has clearly brought new elements and a new vocabulary into the medical decision making process, it has nơ changed the underlying ethical structure. ${ }^{24}$

In fact, an unanticipated benefit of manage care is that light has been shone on patienष्ठ physician relationships, highlighting the dark co: ners and blemishes. That is, so much attention has been devoted of late to exposing the multiple interests and obligations "now" present in the clinical setting, that we have been given, as Patri cia Backler puts it: "a much needed wake-up call alerting us to these long term problems that, for the most part, have been ignored". ${ }^{25}$ Patients are noy being forced to accept what has probably always been true: handing off decision making to even $\dot{g}$ trusted and respected physician is not a guarantec that one's best interest will always be promoted. 을

Hence, at least in this respect, patients have benefited from managed care. And, at least in the respect, physicians' autonomy has suffered: ie their previous near complete control over the clinical setting has been dramatically reduced. They now must answer not only to financial mant agers but also to patients who are more sophist? cated about the factors present in medict decision making and more willing to exercise the own autonomous choices.

\section{Recognising and resolving conflicts}

In short, all decisions, including medical, arब complicated by mixed motives. How then does the conscientious physician make sure the determin ing motives are those that best satisfy existeng ethical obligations? The key, I believe, lies in reak ising that physicians have always faced such 
decisions, ${ }^{27}$ that they have long confronted conflicts of interest, bias, and obligation and, upon careful ethical reflection, have resolved them. Again, managed care brings new factors to consider, but it does not fundamentally alter the structure of medical decision making.

\section{Crucial first step}

Recognising the type of conflict involved is a crucial first step toward its resolution. Resolving conflicts of interest, for example, involves a decidedly different process from those associated with conflicts of bias and of obligation. Avoiding conflicts of interest requires personal honesty, the ability candidly to answer questions such as: "would I recommend this procedure if I did not stand personally to gain from it?"; "would I question the propriety of the decision if it was being made by my closest competitor?"; "would it pass the " 60 Minutes' test?"28 It requires, once the conflicting interest is recognised, a strength of moral will to accept some personal sacrifice so as to carry out the ethically correct choice.

Conflicts of bias are more difficult to recognise, but easier to resolve, ie, once the bias is seen, it does not take a particular strength of will to overcome it. ${ }^{29}$ Recognising bias, however, requires rigorous ongoing self-reflection and evaluation. Appropriate questions here include: "do certain groups make me nervous, impatient, frustrated?"; "do I find myself with certain groups automatically using abbreviated explanations, or acting more paternalistically?"; "if I did a review of patient charts, am I confident I would find no bias-associated patterns in diagnosis or treatment recommendations?" If in doubt, do such a review.

Resolving conflicts of obligation is much more difficult. But they are at the heart of all ethical dilemmas; indeed, many hold that the very definition of an ethical dilemma is the conflict between competing moral obligations. Thus what physicians are now facing in their conflicting obligations to patients and to managed care organisations is by no means unique. The role-engendered nature of the conflicts, and the long history of medicine as a profession with special obligations to patients, certainly make the conflicts complex, but no more so than those faced by other professionals. Lawyers routinely face competing obligations to clients and to court/society; university department chairs must often choose between what is good for the campus as a whole versus the needs of their individual departments, and physicians must choose between what is in the patient's best interest and what their contractual obligations allow.
There is a tendency to "professionalise" such choices, to see them as only involving a conflict between two professional role-based obligations, for example, between the physician's duties to a managed care organisation and her duties to the patient. While one's professional roles clearly can bring competing obligations, to reduce the conflict to role-determined behaviours leaves out another crucial-indeed, I believe decidingconsideration, namely the physician's own values. As Gerald Postema puts it in discussing similar role-based conflicts among lawyers, one must:

"recognise the unavoidable discontinuities in the moral landscape [ie, conflicts of obligation] and ... bridge them with a unified conception of moral personality... . Each lawyer must have a conception of the role that allows him to serve the important functions of that role in the legal and political system while integrating his own sense of moral responsibility into the role itself. Such a conception [enhances] moral judgment in day-to-day professional activities while encouraging a keener sense of personal responsibility for the consequences of those activities." 30

In other words, the core of such choices has to be the physician's own value system. When faced with such dilemmas, one cannot separate one's personal and professional values; these must be bridged by "a unified conception of moral personality". Such a unity avoids the psychic and ethical damage associated with strict role differentiation, while promoting the development of moral judgment - the ability both to recognise core values, not just professional values but general moral values, and to apply these to specific cases. Again, Postema:

"Judgment ... is both a disposition-a trait of character-and a skill which must be learned and continually exercised. It is important, then, if we are seriously to consider matters of moral responsibility in professional contexts, that we pay attention to the conditions of development of this disposition and the exercise of this skill." 31

This development and exercise cannot effectively occur when the physician conceives of herself as merely a "contracting employee of Better Health Inc". Instead, she is "Betty Jones, physician, patient advocate, contracting employee of Better Health Inc, parent, friend, etc". Each role carries ethical obligations, some of which will sometimes conflict with others. Resolving such conflicts entails reflecting upon what her ethical foundations are, as well as what they are for the respective 
roles-ie, what are the ethical purposes behind being a physician, an employee, a parent, a friend?

Understanding these foundations will take one a long way towards resolving the conflicts of obligation that inevitably arise for all physicians, indeed for all persons.

\section{Conclusion}

The primary focus of this article has been to show that despite many claims to the contrary, the types of ethical conflicts now faced by physicians are neither fundamentally different from those they have long faced, nor particularly removed from those faced by other professionals. I have also suggested that recognising the specific type of conflict, whether it be one of interest, of bias, or of obligation, alters both how one should understand its significant elements and how one should attempt its resolution.

If correct, these conclusions reveal that US medicine is hardly dead, and that any efforts necessary to keep it alive and healthy fall squarely upon physicians. They must engage in the often muddy, complex job of sorting among various ethical conflicts, using good moral judgment to preserve the core values of the profession and of the persons involved.

\section{Acknowledgement}

I am grateful for the helpful suggestions given by Bruce Jones, Donna Elsdon Meyers, Robert Woods, and the anonymous reviewers of this journal.

Christopher Meyers, PhD, is Professor of Philosophy and Director, Kegley Institute of Ethics, California State University, Bakersfield, USA.

\section{References and Notes}

1 Staab EV Consensus quest: reshaping the future of radiology. Radiology 1996;198,3:643-50; McDaniel C, Erlen J. Ethics and mental health service delivery under managed care. Issues in Mental Health Nursing 1996;17,1:1 1-20; Webb MS. Medical ethics under managed care: how can the patient survive? Annals of Plastic Surgery 1996;37,3:233-44; Chervenak FA McCullough LB, Chez RA. Responding to the ethical challenges posed by the business tools of managed care in the practice of obstetrics and gynecology. American fournal of Obstetrics and Gynecology 1996;1 175,3 pt 1:523-7; Larkin GL, et al. Managed care ethics: an emergency? Annals of Emergency Medicine 1996;28,6:683-9; Basta L, Taught J. High technology near the end of life: setting limits [editorial]. Fournal of the American College of Cardiology 1996;28,6:1623-30; Sunley R. Advocacy in the new world of managed care. Families in Society 1997;78,1:84-94; Backlar P. Managed mental health care: conflicts of interest in the provider/client relationship. Community Mental Health fournal 1996;32,2: 101-6; Foglio J, et al. What ethicists talk about when they talk about managed care. Hospital Health Network 1996;70,13: $24-5$.
2 Swee DE. Health care system reform and the changin physician-patient relationship. New fersey Medicine 1995;92, 3 . 313-7; Schwartz P. Medical ethics under managed car International Fournal of Fertility and Menopausal Studico 1996;41,2:124-8; Cassel CK. The patient-physician covenan an affirmation of Asklepios. Connecticut Medicine 1996;60, 291-3; Warner EG. Ethics and morality vs managed care. Fou $\underline{\underline{\Omega}}$ nal of the Oklahoma State Medical Association 1996;89,8: 75-9

3 Warner EG. The current healthcare environment: who is the customer? Nursing Forum 1996;31,3:16-21; Erlen JA, Mello@ M. Managed care and the nurse's obligations to patientes Orthopedic Nursing 1995; 14,6:42-5.

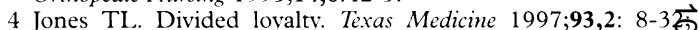
BeSaw L. Conflicts of interest. Texas Medicine 1997;93,5:3841; Tamborlane TA, Schaper T. Conflicts of interest managed care. New fersey Medicine 1995; 92,8:523-5; Perk RL. Ethics and managed care. Medical Clinics of North Ameri 1996;80,2:263-78; Blume E. Hippocratic oath versus manage care: physicians caught in ethical squeeze. Fournal of the National Cancer Institute 1997; 89,8:543-5.

5 McArthur JH, Moore FD. The two cultures and the health care revolution. Commerce and professionalism in medical care fournal of the American Medical Association 1997;277,12: 985-80 Rosner F. The ethics of managed care. Mt Sinai fournal bo Medicine 1997;64,1:8-19.

6 [Anonymous. Unattributed Associated Press story]. Doctors joining unions. The Bakersfield Californian 1997 Mar: A: 13, 15 As this article was being sent to press the 800 physicians wh work for Los Angeles County, California, USA vote? overwhelmingly to join the Union of American Physicians ang Dentists. Riccardi N. LA County doctors vote decisively unionize. Los Angeles Times 1999 May 29: Al, 22.

7 The term "managed care" is admittedly vague because $\vec{\varphi}$ encompasses, in the United States at least, such a range methods for altering the financing of health care service including health maintenance organisations, independent pho sician associations and preferred provider associations. Larry Churchill notes, however: "the common element is som strategy for delivering services in a more efficient wa. Efficiency is achieved ... generally through measures that af geared to assure that only appropriate services are provided Churchill LR. 'Damaged Humanity': The call for a patien? centered medical ethic in the managed care era. Theoretic Medicine 1997;18:118. The main concern for many physician is that in the search for "efficiency" decisions are made for economic, not medical, reasons, and sometimes by accountan rather than trained medical personnel.

8 See reference 7: 119

9 Bernat JL, et al. Attitudes of US neurologists concerning th ethical dimensions of managed care. Neurology 1997;49, $\mathbb{D}$ 4-13.

10 Kipnis K. Conflict of interest and conflict of obligation. Davis M, Eliston FA, eds. Ethics and the legal profession. Net. York: Prometheus Books, 1986: 291

11 See reference 10: 284

12 That conflicts of interest are relatively easy to resolve does ne mean that persons will in fact act accordingly, as evidenced bs the plethora of such conflicts across all professions. Recognis ing one's moral obligation and having the strength of will to a upon it are obviously very different propositions.

13 See reference 2: Warner: 275 .

14 See reference 2: Cassell: abstract.

15 Council on Ethical and Judicial Affairs, American Medictio Association. Conflicts of interest. Physician ownership of medF cal facilities. Fournal of the American Medical Association $199 \mathrm{Rj}$ 267,17:2366-9; Hillman BJ, et al. Frequency and costs of diago nostic imaging in office practice - a comparison of self-referring and radiologist-referring physicians. New England fournal Medicine 1990; 323,23:1604-8.

16 Hodges B. Interactions with the pharmaceutical industr 9 experiences and attitudes of psychiatry residents, interns and clerks. Canadian Medical Association fournal 1995;153,50 553-9; Blake RL Jr, Early EK. Patients' attitudes about gifts to physicians from pharmaceutical companies. American Board Family Practice 1995; 8,6:457-64

17 Gijsbers van Wijk CM, van Vliet KP, Kolk AM. Gend perspectives and quality of care: towards appropriate and adequate health care for women. Social Science and Medicie 1996;43,5:707-20; Fisher S. In the patient's best interest: women and the politics of medical decisions. New Brunswick, NJ: Rutge日 University Press, 1986; Franks P, Clancy CM. Physicia gender bias in clinical decisionmaking: screening for cancer in primary care. Medical Care 1993;31,3:213-8. 
$18 \mathrm{McKenna} \mathrm{RJ}$ Sr. Clinical aspects of cancer in the elderly. Treatment decisions, treatment choices, and follow-up. Cancer 1994; 74 (7 suppl):2107-17.

19 Gerbert B, Maguire BT, Bleecker T, Coates TJ, McPhee SJ. Primary care physicians and AIDS: attitudinal and structural barriers to care. Fournal of the American Medical Association 1991;266,20:2837-42; Kelly JA, St Lawrence JS, Smith S Jr, Hood HV, Cook DJ. Stigmatization of AIDS patients by physicians. American fournal of Public Health 1987;77: 789-91; Nielsen BP, Gallegos DA, Harris DL, Gomez MT. AIDS awareness among rural Utah physicians. Western fournal of Medicine 1991;154,6:689-92.

20 Cotton P. Gay, lesbian physicians meet, march, tell Shalala bigotry is health hazard. Fournal of the American Medical Association. 1993; 269,20:2611-12.

21 Morreim EH. Lifestyles of the risky and infamous: from managed care to managed lives. Hastings Center Report 1995;25:512.

22 Wallsten TS. Physician and medical student bias in evaluating diagnostic information. Medical Decision Making 1981;1, 2:145-64.

23 Cross AW, Churchill LR. Ethical and cultural dimensions of informed consent. A case study and analysis. Annals of Internal Medicine 1982;96,1:110-3; Meyers C. The impact of physician denial on patient autonomy and wellbeing. Fournal of Medical Ethics 1992;18,3: 135-7.

24 Since the time this paper was first submitted for review studies have been released which reveal that managed care may be having a greater negative impact on traditionally underserved populations, particularly non-white and poor, through the exclusion of "physicians who provide a greater share of charity care. Rather than rewarding these physicians for their socially responsible deeds, the health care marketplace seems to be excluding them," and, by consequence, their poor, non-white patients. Bindman $A B$, Grumbach $K$, Vranizan $K$, Jaffe $D$, Osmond $\mathrm{D}$. Selection and exclusion of primary care physicians by managed care organizations. Fournal of the American Medical Association 1998; 279,9:679. (Similar conclusions were drawn by Secundy $M$ and Dula $A$ in their respective panel presentations, Ethical issues in managed care. Association for
Applied and Professional Ethics annual meeting, Dallas, Texas, USA, February 28,1998 .) While this is clearly a troubling consequence of managed care, it does not represent a new ethical dilemma. US health care has long struggled with adequately serving all segments of the population. It may be, as noted above, that the solution can only be found in a fundamental restructuring of the US system.

25 See reference 1: Backlar: 101-106.

26 Woolf SH. Practice guidelines: a new reality in medicine. III Impact on patient care. Archives of Internal Medicine 1993; 153,23: 2646-55; Mechanic D. Physicians and patients in transition. Hastings Center Report 1985;15,6:9-12; Bellin LE. The shrinking autonomy of the practising physician and its impact on quality. Fournal of Community Health 1986;11:155-64; Mirvis DM. Physicians' autonomy - the relation between public and professional expectations. New England fournal of Medicine 1993;328,18:1346-9; Nornhold P. Power: it's changing hands and moving your way. Nursing 1986;16:40-2; Daniels N. Understanding physician power: a review of the social transformation of American medicine. Philosophy and Public Affairs 1984;13:347-57, esp 353-7.

27 "Some problems in the doctor-patient relationship currently exist [and] ... will exist regardless of the finance and delivery system (eg, the physician's ancient personal struggle between altruism and self-interest)". La Puma J. Anticipated changes in the doctor-patient relationship in the managed care and managed competition of the Health security Act of 1993 . Archives of Family Medicine 1994; 3,8:665-71.

28 Ie, "Would I be particularly nervous should Mike Wallace (or some other reporter) show up at my office door to ask questions about this decision?" (Hulpke J. Personal communication, 1990. Professor Hulpke uses this test in his business ethics courses.)

29 This assumes, of course, the conscientious physician wishes to rid herself and her decisions of all bigotry-racial, ethnic, gender, sexual preference, etc.

30 Postema GJ. Moral responsibility in professional ethics. See reference 10: 171 .

31 See reference 30: 161

\section{News and notes}

\section{Fifth World Congress of Bioethics}

The International Association of Bioethics has announced that the Fifth World Congress of Bioethics will take place at Imperial College, London from 21-24 September 2000.

Associated organisations are: The British Association for the Advancement of Science; the British Medical Association; the European Association of Centres of Medical Ethics; the Institute of Medical Ethics; the Millenial Festival of Medicine; the Nuffield Council on Bioethics; the Royal College of Nursing; the Royal
College of Psychiatrists, Philosophy Special Interest Group; the Society for Applied Philosophy; the UK Forum for Healthcare Ethics and Law, and the World Health Organisation.

For further information (and to obtain a preliminary programme, in September/October 1999) please contact: Sara Hassen, 5th World Congress of Bioethics, 1 Riverside, St Anne's Road, Bristol, BS4 4ED or email: enquiries@inanyevent-uk.com or use the Congress Website at http://www.uclan.ac.uk/facs/ethics/fifthcon.htm 